ISSN 1518-3483

Licenciado sob uma Licença Creative Commons

\title{
Dilemas e aprendizagens profissionais de professores iniciantes de educação física
}

\section{Dilemmas and apprenticeships professional of beginning \\ teachers of physical education}

\author{
José Ângelo Gariglio ${ }^{[a]}$, Carolina Guimarães Reis ${ }^{[b]^{*}}$ \\ [a] Universidade Federal de Minas Gerais (EEFFTO/UFMG), Belo Horizonte, MG, Brasil \\ [b] Pontifícia Universidade Católica de Minas Gerais (PUC Minas), Belo Horizonte, MG, Brasil
}

\section{Resumo}

Este texto relata alguns dos resultados de nossa pesquisa que teve como objeto de estudo central a análise dos processos de iniciação à docência de licenciados em Educação Física (EF). O estudo tem como objetivos identificar quais as percepções que professores de Educação Física iniciantes têm deste ciclo de desenvolvimento profissional; analisar como professores de Educação Física iniciantes pensam e atuam profissionalmente de forma a integra-se às situações de trabalho; entender como os professores iniciantes aprendem a ensinar nos primeiros anos de exercício profissional na escola. A pesquisa lançou mão dos seguintes instrumentos de coleta de dados: realização de entrevistas com docentes iniciantes e análise de casos de ensino confeccionados por meio de relatos escritos. Nosso

\footnotetext{
* JAG: Doutor em Educação, e-mail: angelogariglio@hotmail.com

CGR: Pós-graduada em Ensino de Educação Física, e-mail: carolguir@yahoo.com.br
} 
estudo aponta para o caráter situado da iniciação à docência no qual se podem verificar singularidades de experiências e percepções sobre esse ciclo de desenvolvimento profissional. Esse caráter contextual da inserção profissional mostrou-se fortemente relacionado ao campo disciplinar (EF) a qual os professores pertencem.

Palavras-chave: Professores de Educação Física. Professores Iniciantes. Aprendizagem docente.

\section{Abstract}

This paper reports some results of our research where the main object of study to analyze the processes of initiation to teaching graduates in physical education (PE). The study aims to identify the perceptions that physical education teachers beginners have this professional development cycle; analyze how Physical Education teachers beginners think and act professionally so integrated with the work situations; understand how beginning teachers learn to teach in the early years of professional experience in school. The research made use of the following data collection tools: interviews with beginning teachers and analysis of teaching cases made through written reports. Our study points to the character set of the initiation to teaching in which to check uniqueness of experiences and perceptions of this professional development cycle. This contextual character of employability was strongly related to the disciplinary field (EF) which teachers belong.

Keywords: Teachers of Physical Education. Beginning teachers. Teacher learning.

\section{Introdução: O problema de pesquisa}

Nos últimos trinta anos parte das literaturas internacional e nacional que trata da formação de professores vêm buscando compreender melhor os processos de socialização e desenvolvimento profissional dos docentes. Esses estudos visam, entre outros objetivos, compreender de que maneira os professores dão sentido a sua vida profissional e de que forma se entregam a ela como atores cujas ações e projetos contribuem 
para definir e construir sua carreira. Nesta perspectiva, entende-se a modelação da carreira docente situada na confluência entre a ação dos indivíduos e as normas e papéis que decorrem da institucionalização das ocupações, papéis que estes indivíduos devem interiorizar e dominar para fazerem parte da profissão docente.

Estes estudos sobre a carreira docente permitiram conhecer melhor a dimensão historicamente construída dos saberes, do saber-fazer e do saber-ser professor e de que forma estes saberes são incorporados às atitudes e comportamentos dos professores por intermédio de sua socialização profissional no campo da formação e atuação docente. Desse ponto de vista, os estudos sobre a carreira permitiram analisar mais detidamente a fundamentação da prática do professor — o que ele é e faz — em sua trajetória profissional (TARDIF, 2002; TARDIF \& RAYMOND, 2000).

Sustentados por essa perspectiva de análise, vários autores no campo dos estudos sobre a formação de professores vêm tratando a carreira docente como um contínuo formativo marcado pela presença de ciclos ou fases de desenvolvimento profissional. Michael Hubernam (1974; 2000) ao construir reflexões sobre essa hipótese, levanta questões que, para o autor, ainda precisam ser tratadas de forma mais consistente. Dentre essas questões destacamos três que expressam mais claramente o que os estudos sobre os ciclos de desenvolvimento profissional de professores almejam conhecer mais de perto: será que todos os professores passariam pelas mesmas etapas, as mesmas crises, os mesmos acontecimentos, o mesmo termo de carreira, independente da geração a que pertencem, ou haverá percursos diferentes, de acordo com o momento histórico da carreira? Que imagem essas pessoas têm de si, como professores, em situação de sala de sala de aula, em momentos diferentes da sua carreira? Terão a percepção de que modificam os seus processos de animação, a sua relação com os alunos, a organização das aulas, as suas prioridades ou domínio da matéria que ensinam?

$\mathrm{Na}$ busca por construir respostas a estes questionamentos, algumas pesquisas sobre tema vêm tentando nomear ou classificar quais seriam e como se caracterizariam os diferentes ciclos de vida profissional 
dos professores. Dentre os estudos mais famosos sobre o tema é emblemático a pesquisa feita por Michael Huberman sobre o ciclo de vida profissional de professores do ensino médio. Nessa investigação o autor classifica as fases da carreira docente em cinco momentos: de 1 a 3 anos seria a fase de entrada e tatiamento da profissão; de 4 a 6 anos de estabilização e consolidação de um repertório pedagógico; de 7 a 25 anos de diversificação, ativismo e questionamento; de 25 a 35 anos de serenidade, distanciamento afetivo e de certo conservadorismo e de 35 a 40 anos uma fase caracterizada pelo desinvestimento profissional e amargura com a profissão ou de serenidade.

No caso específico do nosso estudo ${ }^{1}$, nos interessa investigar os processos de iniciação na docência (a fase de entrada e tateamento da profissão) de estudantes de Educação Física licenciados. Esse ciclo é denominado pela literatura de diversas formas, a ver: choque da realidade, choque de transição ou choque cultural. Esses termos buscam retratar ou significar aspectos da transição da vida de estudantes para a vida mais exigente de trabalho e o confronto inicial com a difícil e complexa realidade do exercício da profissão.

A entrada na carreira profissional é vista por Tardif e Raymond (2000) como um período que duraria aproximadamente sete anos, divididos em duas fases com características singulares. A fase de exploração (de um a três anos) na qual o professor escolhe provisoriamente a sua profissão inicia-se através de tentativas e erros, sente a necessidade de ser aceito por seu círculo profissional (alunos, colegas, diretores de escolas, pais de alunos) e experimenta diferentes papéis. Essa fase variaria de acordo com os professores, pois pode ser fácil ou difícil, instigante ou decepcionante e condicionada pelas limitações e possibilidades de uma dada instituição escolar. A segunda fase seria tida como de estabilização e de consolidação (de três a sete anos), em que o professor investe a longo prazo na sua profissão e os outros membros da instituição reconhecem as suas capacidades. Além disso, essa segunda fase se caracterizaria por

1 Esta pesquisa contou com os financiamentos da UFMG, CNPq, FAPEMIG e CAPES. 
uma confiança maior do professor em si mesmo (e também dos outros agentes no professor) e pelo domínio dos diversos aspectos do trabalho, principalmente os pedagógicos (gestão de classe, planejamento do ensino, apropriação pessoal dos programas), o que se manifesta através de um melhor equilíbrio profissional.

Estudos têm mostrado que o choque da realidade traduz-se na necessidade de absorção pelas inúmeras informações que lhe chegam, a visualização da totalidade da escola e a relação com os alunos; o contato com os outros docentes; a descoberta e a necessidade de ter que dar conta de questões burocráticas da sala de aula como preencher o diário de classe ou ainda planejar sua aula; dentre outras tantas tarefas. Além do enfrentamento de uma nova situação profissional, os professores que iniciam a carreira, geralmente recebem as salas mais complicadas; ressentem-se da falta de colaboração e apoio por parte dos professores mais experientes da escola; passam por um aumento do estresse no primeiro ano de docência; são cobrados, por parte da escola, com as mesmas exigências que os professores mais antigos (GARCIA, 2007, FERREIRA, 2005; FONTANA, 2000).

Concomitantemente, as pesquisas também têm mostrado que a entrada na profissão é vivida como uma descoberta positiva. O professor iniciante traduziria o entusiasmo inicial, a experimentação, a exaltação por estar, finalmente, em situação de responsabilidade (ter sua sala de aula, os seus alunos, o seu programa), por sentir parte de um determinado corpo profissional. Com muita frequência, a literatura tem indicado que os dois aspectos, o da descoberta e o da sobrevivência, são vividos em paralelo e é o segundo aspecto é que permitiria suportar o primeiro (HUBERMAN, 2000).

A importância dos estudos que tratam da entrada na profissão tem recebido cada vez mais reconhecimento, pois esse ciclo profissional é tido como um período crítico de aprendizagem intensa da profissão docente. Esses anos iniciais constituem um período realmente importante da história profissional do professor, determinando inclusive seu futuro e sua relação com o trabalho (TARDIF \& RAYMOND, 2000, GARCIA, 2009). Essa fase é tão crucial que pode levar uma porcentagem importante de 
iniciantes a abandonar a profissão ${ }^{2}$ ou se questionarem sobre essa escolha profissional, a sua continuidade e o desejo de investimento formativo dentro da profissão.

\section{Professores principiantes de Educação Física: uma iniciação à docência singular?}

Os estudos de cunho sociológico, ao se contraporem a perspectiva psicológica do ciclo da vida, colocam-se críticos à ideia de que as sequências da vida seriam pré-determinadas e invariáveis, que todos os professores passariam pelas mesmas fases, dentro de uma mesma ordem, independentemente das condições de formação e trabalho. Diferentemente desse modelo de causalidade, abordagem sociológica tem apontado que a organização profissional é que cria, arbitrariamente, as condições de entrada, empenhamento, promoção e que conferem sentido às fases de desenvolvimento da profissão (HUBERMAN, 1992).

Trazendo esse debate para o campo da profissionalização docente Lessard et al. (2003), chamam a atenção para o fato de que o mundo dos professores aparece como uma diversidade ao plano das identidades profissionais afirmadas. Tal diversidade é marcada fortemente pelas condições de trabalho realmente efetuadas pelos diferentes subgrupos de professores, pelas missões educativas específicas e redefinidas por eles. Os professores se constituem na realidade numa multiplicidade de subgrupos com a sua própria identidade, a sua experiência do sistema escolar, vivendo tensões com outros subgrupos e com o quadro institucional.

Feinama-Nemser et al. (1998) reforçam a tese de que existiriam, no campo de atuação profissional, não apenas uma, mas várias culturas docentes. Para eles, a cultura profissional pode ser considerada como um conjunto de sentimentos partilhados, de hábitos mentais e de modelos

2 Segundo estudos realizados por Gold (1996), cerca de 33\% dos professores abandonam a profissão nesse ciclo da carreira profissional. 
de interação com os alunos, os colegas, os administradores e os parentes. Essa cultura profissional compreenderia também para eles as recompensas intrínsecas, associadas ao exercício do métier.

Esse debate sobre a contextualidade dos saberes profissionais nos instiga a pensar sobre a existência de culturas docentes diferenciadas, isto é, a existência de formas diferenciadas de saber-ser, saber-fazer peculiares a cada subgrupo de professores e suas realidades de trabalho específicas (professores de educação infantil, ensino fundamental, ensino médio, educação profissional, de portadores de necessidades especiais e professores dos diferentes campos disciplinares do currículo escolar). Como afirma Dubar (1997), o espaço de reconhecimento das identidades é inseparável do espaço de legitimação dos saberes e das competências associadas às identidades. A transação objetiva entre indivíduos e as instituições são antes de tudo aquela que se organiza à volta do reconhecimento e do não-reconhecimento das competências, dos saberes e das imagens de si que constituem os núcleos duros das identidades reivindicadas.

Poderíamos dizer então que é, também, na relação específica com as situações particulares de ensino que os saberes da base da ação profissional ganhariam sentido e validade. Seriam, portanto, saberes intimamente relacionados à situação de trabalho à qual devem atender. Nesta ordem de pensamento, parece-nos instigante questionar em que medida as experiências de iniciação a docência, vividas por professores de professores de EF, guardam relação com a especificidade pedagógica da EF, as funções atribuídas pela cultura (escolar e não escolar) ao componente curricular que ensinam, com o lugar ocupado pela Educação Física na hierarquia dos saberes escolares, com do tipo de interação estabelecidas com alunos, com as condições ambientais onde estes professores exercem o seu ensino (sua sala de aula), com os seus objetos didáticos, dentre outras características que demarcam as condições de trabalho situadas.

Pesquisas no campo da Educação Física escolar ${ }^{3}$ tem mostrado que o olhar mais atento dirigido ao cotidiano escolar vai identificar que,

3 FARIA et al. (2009); MACHADO et al. (2009). 
apesar da Educação Física estar presente no currículo em função de uma determinação do marco legal da educação, essa disciplina apresenta no conjunto da cultura escolar um déficit crônico de legitimidade o que faz com que os seus responsáveis e partidários, particularmente os professores de Educação Física, estejam envolvidos numa constante luta por reconhecimento. Essa evidência não é nenhuma novidade, entretanto é interessante observar que isso se dá, entre outros motivos, pela desvalorização da sua especificidade. A visão que se tem é a da Educação Física como auxiliar de outras disciplinas, uma espécie de apêndice da escola. Em observações do cotidiano escolar podem-se perceber gestores da escola e professores de outras disciplinas referindo-se ao momento da aula de Educação Física como espaço de distração para os alunos, no qual eles fugiriam e compensariam a tensão proporcionada pelo esforço intelectual em sala de aula. Há uma grande dificuldade de percepção pelos agentes escolares da aula de Educação Física como um momento de aprendizado sistematizado e com objetivos de ensino próprios, com importância para o desenvolvimento humano dos alunos. A inserção atual da Educação Física na vida das escolas é, na maioria dos casos, potencialmente geradora de manifestações de desrespeito à Educação Física e aos seus professores. As pesquisas vêm mostrando que a visão (e as ações) que os demais agentes escolares têm da Educação Física, particularmente diretores e demais professores, justifica que ela seja entendida como uma "disciplina de se-

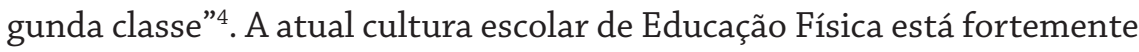
permeada por essa condição. Essa desvalorização configura-se, às vezes, como uma forma de desrespeito nas dimensões do direito e da estima social dos professores, que os motivam à luta por reconhecimento ou então, os levam a uma condição de desinvestimento. O seu não reconhecimento como disciplina escolar pode ser geradora de um movimento coletivo de resistência, mas também, geradora de movimentos de desinvestimento tanto pessoal e profissional de determinados professores. Tal realidade incide, portanto, diretamente na vida dos seus professores uma vez que

4 JEBER (1996); GARIFLIO (1997) 
esses acabam desenvolvendo uma compreensão de si como docentes também de "segunda classe", pelo menos numa posição inferior aos professores das demais disciplinas escolares (BRACHT; FARIA, 2010).

Paralelamente a esta realidade de dificuldades no enfrentamento deste déficit crônico de legitimidade da EF no currículo escolar, os professores de Educação Física deparam-se com outros desafios colocados pelo caráter singular e próprio do ensino deste componente curricular. Algumas das características dessa contextualidade pedagógica da EF foram descritas em pesquisa realizada por Gariglio (2004) com professores de uma escola profissionalizante. Os dados do seu estudo apontam que os professores de EF precisam a aprender a lidar com modalidades de ordem e disciplina diferenciadas em relação à maioria das demais disciplinas escolares (ensinar mediante a presença constante de ruídos — risos, gritos, conversas - , e com intensa movimentação dos alunos e com a ocupação mais livre dos espaços); com a singularidade das condições ambientais da sala da aula da EF (a incidência forte do sol, do frio e de espaços e limites físicos mais amplificados em relação à sala de aula tradicional); o cuidado e a atenção com a segurança e a integridade física em função da movimentação corporal dos alunos; a carência quase que absoluta de material didático orientador da ação pedagógica, proporcionando, ao mesmo tempo, maior autonomia na condução do trabalho pedagógico e sensação de desamparo em face da carência de referências ordenadoras da prática pedagógica; a necessidade de desenvolver tecnologias de comunicação/ interação humana com potencial de persuasão dos alunos em razão da diluição de relações hierárquicas mais verticalizadas na relação professor/ alunos, desestabilizadas pela percepção dos alunos do caráter "inútil" da EF na luta por uma vaga na universidade ou mesmo no mercado de trabalho. Nesse ambiente de ensino mostrou-se imperioso aos professores pesquisados desenvolvessem estratégias de implicação dos alunos nas aulas de EF, não tanto pelos mecanismos de controle muito presentes nas demais disciplinas (risco da reprovação mediante avaliação em provas e testes), mas por canais de comunicação e interação humana, capazes de persuadi-los, seja pela motivação impressa pela ação dos professores, seja 
pela empatia nutrida pelos discentes em relação aos docentes, seja também pela habilidade de tornar os conteúdos de ensino agradáveis e prazerosos aos olhos dos alunos.

Tomando esse debate como referência geradora do nosso estudo, nos pareceu importante desenvolver uma pesquisa sobre a experiência de iniciação a docência vivida por licenciados em Educação Física. Com a pesquisa buscamos encontrar respostas para as seguintes questões: como esses egressos pensam e agem na profissão nos primeiros anos de contato com a docência? Quais os principais desafios enfrentados pelos professores de Educação Física iniciantes? Qual a relação entre a iniciação à docência e a especificidade do ensino da Educação Física na escola?

\section{Metodologia}

\section{Os sujeitos da pesquisa}

A primeira parte da pesquisa foi realizada com 13 licenciados/ as formados/as (4 homens e 9 mulheres) pela Escola de Educação Física, Fisioterapia e Terapia Ocupacional (EEFFTO) da UFMG, nos últimos quatro anos (do final de 2009 em diante) ${ }^{5}$ e que tivessem no máximo três anos de experiência com a docência em EF na escola. A segunda parte da investigação foi realizada com 7 docentes (2 homens e 5 mulheres) dos 13 licenciados citados acima. A opção por trabalhar com licenciados/as formados apenas em uma única instituição teve como objetivo a produção de análises que visassem estabelecer relações mais críveis entre o currículo da formação inicial e sua repercussão frente os desafios colocados pelas situações de trabalho próprias de contexto de iniciação à docência em Educação Física na escola.

5 Os alunos que finalizaram sua licenciatura nesse período tiveram um percurso formativo dentro de um currículo novo, formatado dentro das normativas estabelecidas pelas Diretrizes Curriculares Nacionais para a formação de professores da Educação Básica (Resolução CNE/CP/01 de 2002). 


\section{Técnica de coleta de dados}

\section{Casos de ensino}

Investigadores da epistemologia da prática (L.S.Shulman, 1992; Schön, 1992; Merseth, 1990; entre outros) têm destacado a importância do conhecimento de casos de ensino na construção do pensamento e das práticas do professor. Os casos de ensino surgem como instância da prática e parecem oferecer oportunidades para exame e reflexão sobre a prática de sala de aula. Eles apresentam situações de ensino, descritas detalhadamente, que possibilitam aos futuros professores refletir sobre eventos ocorridos em um determinado contexto. Shulman (1992) afirma:

O conhecimento de casos é um conhecimento de eventos específicos, bem documentados e bem descritos. Enquanto os casos em si mesmos são informações de eventos ou seqüências de eventos, o conhecimento que representam é que os converte em casos. Os casos podem ser exemplos de aspectos concretos da prática - descrições detalhadas de como ocorreu um evento - completados com informação sobre o contexto, os pensamentos e os sentimentos (p. 58).

A análise e a elaboração de casos de ensino podem permitir aos futuros professores desenvolver e explicitar seu conhecimento profissional, já que possibilita o estudo de várias temáticas relacionadas a diversas áreas de conhecimento; a revisão de concepções sobre ensino, aprendizagem, aluno, disciplina, avaliação, dificuldades de aprendizagem etc. Ao mesmo tempo, os casos de ensino constituem-se em

[...] importantes instrumentos de pesquisa - ao possibilitar não apenas apreender as teorias pessoais dos professores, o processo de construção de conhecimentos profissionais, o desenvolvimento do raciocínio pedagógico, como também compreender o pensamento do professor (Mizukami, 2000, p. 156). 
Considerando o potencial dos casos de ensino como instrumentos de pesquisa capazes de [...] possibilitar a apreensão e o desenvolvimento das teorias práticas de ensino que constituem o conhecimento profissional do professor (Mizukami, 2000, p. 140), apostamos nesse procedimento metodológico por entender ser este um poderoso instrumento de acesso e reflexão sobre as situações práticas vividas pelos professores iniciantes - como um determinado professor enfrenta o desafio de ensinar os conteúdos de sua disciplina, como ele lida com os conflitos com os alunos, como ele se relaciona com as normas da cultura institucional da escola, como experimenta a convivência cotidiana com os seus pares. Os casos de ensino apresentam, portanto, [...] um retrato de uma situação-problema enfrentada por um professor, uma variedade de abordagens possíveis que poderiam ter sido adotadas e algumas informações sobre como o problema foi resolvido (Mizukami, 2000, p. 152).

Realizamos análise de 7 textos escritos de casos de ensino, confeccionados por 7 dos 13 professores que já haviam nos concedido uma primeira rodada de entrevistas. Tal descrição reflexiva sobre essa experiência prática levou em conta duas vertentes fundamentais: a referencial e a existencial (ZABALA, 1994). A vertente referencial descreve o objeto narrado, ou seja, as características dos alunos, os objetivos da aula, as situações da escola. Já a vertente existencial narra sobre si mesmo, o que envolve as decisões do professor, as emoções e as intenções.

\section{Entrevistas}

Realizamos duas entrevistas semiestruturadas, sendo uma primeira com 13 professores/as (5 homens e 9 mulheres) e uma segunda com 7 docentes ( 2 dois homens e 5 mulheres). A primeira entrevista foi construída levando em consideração 4 eixos aglutinadores: as percepções sobre a iniciação à docência; as ações e estratégias pensadas e realizadas pelos professores com vistas ao enfrentamento da realidade; as aprendizagens docentes mais significativas e a relação entre a formação inicial e a 
iniciação à docência. A segunda entrevista foi realizada com os 7 docentes que enviaram os casos de ensino por escrito. Nela pretendíamos aprofundas as análises dos textos escritos, em especial, os processos de aprendizagem docente. Com as entrevistas, buscamos respostas para duas questões: como os professores se apercebem da situação precisa perante a qual se encontram nesse momento da carreira? Como esses professores pensam e agem mediante a experiência de iniciar a docência no campo da intervenção pedagógica em EF?

\section{Considerações finais}

A nossa pesquisa encontra-se neste momento em fase inicial de análise do material coletado, em especial, dos dados decorrentes da realização das entrevistas com 13 professores iniciantes de Educação Física. Nos parágrafos seguintes, vamos discorrer sobre algumas impressões iniciais sobre os processos de inserção profissional vividos por esses docentes.

O primeiro dado que surge dos discursos de alguns professores e que tem nos chamado a atenção é o fato de que a inserção profissional em etapas da educação básica mais iniciais (educação infantil e séries iniciais do ensino fundamental) potencializa um sentimento mais positivo da docência. Isso porque, nessa experiência docente, seriam minimizados possíveis tensões e desgastes fruto da relação estabelecida com os alunos. Os professores argumentam que tal experiência é provocada sobretudo pela grande motivação das crianças pelo ato de brincar e pelo movimentar-se corporal. O engajamento das crianças nas aulas de EF parece acelerar os processos de socialização profissional, principalmente no que tange à autopercepção do que é ser professor.

Nesse panorama de ensino-aprendizagem situado, potencializa-se um sentimento de entusiasmo inicial com a profissão e de exaltação por se sentir parte da profissão docente. Tal situação, segundo a fala dos professores, parece catalisar também os processos de alargamento da 
experimentação pedagógica, já que a diluição das tensões na relação com os alunos possibilitaria a eles voltar sua atenção para questões de ordem didática.

Vinculada a essa percepção de que o choque da realidade seria amenizado pela representação positiva que as crianças teriam em relação às aulas de EF e de seus professores, os nossos sujeitos de pesquisa, ao discorrem sobre a sua percepção sobre a iniciação à docência, relatam que a experiência de ensinar em EF possibilitar-lhes-ia outro tipo de relação com os estudantes e com o ato de ensinar. Isso porque a experiência de ensinar os conteúdos da EF (jogos e brincadeiras, danças, lutas, ginásticas), talvez pela percepção dos professores de que a ação didática em EF é mais rica em experimentações corporais, via o movimentar-se humano, daria a eles maior acesso aos alunos e, por consequência, produziria outro tipo de relação com os estudantes. Tal contexto de ensino e aprendizagem proporcionaria aos professores de EF um conjunto mais ampliado de informações sobre os sujeitos de sua intervenção pedagógica, o que os ajudaria a incrementar estratégias de ensino voltadas à motivação dos alunos em participar das aulas de EF.

Tal realidade mostra-se relacionada com o tipo de enfrentamento vivido por esses professores na escola. A necessidade premente de desenvolver tecnologias de comunicação/interação humana com potencial de persuasão dos alunos tem relação direta com o fato de que, na cultura escolar em geral, a EF é muitas vezes reconhecida pelos demais agentes escolares, particularmente diretores e demais professores, como uma "disciplina de segunda classe".

Nesse contexto, a produção da autoridade docente não se dá como em outras disciplinas da escola. Na Educação Física, as relações hierárquicas e de poder entre alunos e docentes são diluídas, uma vez que esses docentes têm menos condições de operar uma relação de controle e implicação dos alunos nos termos verificados nas demais disciplinas escolares. As recompensas extrínsecas, materializadas no peso de avaliações (provas) e dos riscos constantes de reprovação do ano letivo, mais 
próprias ao contexto de ensino da maioria das disciplinas, devem ser substituídas pela recorrência de motivações intrínsecas.

Nesse ambiente de ensino, é preciso implicar os alunos nas atividades não tanto pelos mecanismos da coerção, mas por canais de comunicação e interação humana, capazes de persuadi-los, seja pela motivação impressa pela ação dos professores, seja pela empatia nutrida pelos discentes em relação aos docentes, seja também pela habilidade de tornar os conteúdos de ensino agradáveis e prazerosos aos olhos dos alunos.

Foi recorrente na fala dos professores que um dos maiores desafios vividos por eles na fase da iniciação à docência é convencer os alunos a participar das aulas de EF. Tal realidade, ao mesmo tempo em que os instiga a construir canais de comunicação e diálogo com os alunos, é também geradora de angústias e estresse. Primeiro, porque esses professores não possuem ainda mecanismos referentes muito elaborados que os habilitem na arte de convencer e "dobrar" os estudantes. Segundo, porque se verificou que, na maioria das escolas, não há apoio direto da gestão escolar ou da supervisão pedagógica da escola que suporte a ação dos professores de Educação Física na direção do convencimento dos estudantes de que a disciplina não é mera atividade, mas sim um componente curricular como os demais que constituem o currículo escolar. Com isso, recai sobre esses docentes a responsabilidade quase que solitária e o desgaste dela proveniente da ação de negociação junto aos estudantes.

Sobre tal ponto, é importante ressaltar que alguns professores que participaram da nossa pesquisa têm conseguido algum sucesso nessa empreitada. Para isso, para além das ações e estratégias de negociação junto aos alunos, esses têm buscado um diálogo com a escola, quer em supervisão pedagógica, quer em gestão escolar, quer com os pares (docentes de outras disciplinas). Essa postura de desprivatização da prática (COCHRAN-SMITH, 2014) por parte dos professores parece ser elemento muito significativo no alcance do reconhecimento da EF como disciplina escolar e, via de consequência, a um desenvolvimento profissional docente marcado por uma percepção mais positiva acerca da docência. O individualismo pedagógico mostrou-se um empecilho à constituição de 
uma experiência de iniciação à docência que intensifique o processo de descoberta da profissão, ou seja, de entusiasmo, de experimentação, de exaltação de situação e responsabilidade próprias do ofício docente (de educar crianças e jovens, de construir um programa de ensino), da construção da autoridade docente e de um sentimento de pertencimento de um corpo profissional. Os dados apontam que o fato de que uma inserção marcada pelo individualismo pedagógico reforçaria, para esses docentes, os aspectos sofridos da sobrevivência ou do que choque do real.

Paralelamente, a fala dos nossos sujeitos de pesquisa aponta também para múltiplas situações de desrespeito profissional provenientes das intervenções dos agentes escolares. Entre essas, a tentativa de desmobilização dos estudantes para participarem das aulas de EF, a não inserção desses professores no debate das questões pedagógicas da escola, a inexistência de investimento na qualificação do material didático específico da EF, a interferência não negociada ante as ações de planejamento e organização curricular da EF produzida pelos professores e a instrumentalização da EF e de seus professores na construção de eventos escolares com vistas à publicidade da "marca" da escola junto ao mercado (no caso das escolas privadas) e/ou impondo uma disponibilidade à organização desses eventos, independentemente do que esses docentes propunham em suas aulas. Este último ponto mostra um reconhecimento mais ligado a fatores extracurriculares do que à aprendizagem específica sobre os saberes específicos da disciplina.

Em algumas das escolas onde esses docentes atuam, a representação que se tem é a da Educação Física como auxiliar de outras disciplinas, uma espécie de apêndice da escola, como espaço de distração para os alunos e como lugar de esquecimento das tensões proporcionadas pelo esforço intelectual em sala de aula. Há grande dificuldade de percepção pelos agentes escolares da aula de Educação Física como um momento de aprendizado sistematizado e com objetivos, com importância para o desenvolvimento humano dos alunos. Essa desvalorização configura-se, às vezes, como forma de desrespeito nas dimensões do direito e da estima social desses professores, que os motivam, por um lado, à luta por reconhecimento ou, então, 
levam-nos a uma condição de desinvestimento profissional (BRACHT; FARIA, 2010). Tal condição tem exigido desses professores triplo esforço: ensinar, aprender a ensinar e convencer os pares que aquilo que eles ensinam tem algum valor à formação cultural dos estudantes.

O segundo achado que emerge dos dados da nossa pesquisa tem relação com a dificuldade encontrada pelos professores em saber organizar didaticamente o ensino da Educação Física no currículo escolar. Tal estorvo é motivado, segundo os professores, pelo fato de existirem poucas referências didáticas que possam auxiliá-los nesse processo de organização curricular da EF. A maioria das escolas nas quais esses professores trabalham não apresenta orientações ou prescrições rígidas nessa direção. Os professores relatam que, na Educação Física, não há definição clara a priori de quais conteúdos serão trabalhados durante o ano, de como organizá-los no tempo escolar e num diálogo mais orgânico com o projeto escolar. Esse fato revela alto grau de autonomia dos professores de EF em relação ao tratamento dos conteúdos de ensino.

Na maioria dos casos, não há, por parte dos seus pares nem do setor pedagógico da escola, cobranças rígidas de prestação de contas, avaliação ou acompanhamento do trabalho desses professores. Consequentemente, não há necessidade de esses cumprirem determinado cronograma de transmissão de conteúdos em função de datas em que os alunos deveriam ter tido acesso, dado o período das avaliações escolares ou de outras datas determinadas pelo calendário escolar. Externamente às escolas, tal fato tem o seu correlato na medida em que se verifica que o mercado editorial de livros didáticos nesse campo (EF) é ainda muito restrito (em quantidade e pluralidade).

Assim, sem a presença do livro de didático, o ato de planejar o ensino se apresenta como um dos maiores desafios para esses professores. Que conteúdos ensinar? Como organizar os conteúdos no tempo escolar? Quais os objetivos a alcançar? Qual a periodicidade para cada conteúdo? Como tratá-los segundo as diferentes fases da vida dos estudantes? Como relacioná-los com o projeto escolar? 
Em função da inexistência do peso dos livros didáticos na determinação das tarefas escolares, da maior margem de autonomia dada pela escola ao ato de organização do planejamento de ensino, do distanciamento da EF em relação ao cronograma de avaliações das escolas, do baixo controle externo sobre essa disciplina (avaliações estandardizadas não avaliam a EF, inexistência da cultura do livro didático), somada ao pouco interesse de regulação interno à escola sobre a EF, acabam por influenciar a relação desses professores com o ato de planejar. Mais do que os prazos a cumprir, são as pessoas (as necessidades e os interesses dos alunos e as crenças pessoais dos próprios professores de EF), as peculiaridades do contexto imediato (as necessidades internas da vida escolar e dos alunos) e o cumprimento de determinados objetivos prioritários (a formação humana dos alunos, a luta pela legitimação da EF) que contribuem para organizar a intervenção dos professores durante um ano letivo.

Esse contexto situado de trabalho, ao exigir desses professores intensificação de uma ação reflexiva sobre o seu fazer pedagógico, parece também tornar mais fortes os processos de aprendizagem docente (ofício do ensino) na medida em que aviva as experiências de socialização profissional ${ }^{6}$, via o alargamento do conhecimento sobre a cultura escolar. Tal socialização profissional, segundo a fala dos nossos sujeitos de pesquisa, está relacionada à aprendizagem sobre a especificidade pedagógica da EF; sobre as características dos estudantes e de suas demandas de aprendizagem; de competências necessárias ao ato de planejar o ensino em EF; de saber como construir coletivamente o planejamento de ensino, da construção de técnicas, sequências e recursos didáticos, dado a inexistência de livros-texto que orientem o ensino na sala de aula; de criação de tecnologias de interação e comunicação com os estudantes (saber falar como eles, saber negociar, saber relacionar); a aprendizagens relacionadas ao ensino de conteúdos da EF não tratados e/ou tratadas de forma inadequada na

6 Entendemos "socialização profissional" como o processo mediante o qual o indivíduo adquire o conhecimento e as destrezas sociais necessárias para assumir um papel na organização escolar (VAN MAANEN, 1979). 
formação inicial e de aprender a lidar com certos conteúdos da EF com os quais os professores não construíram intimidade corporal (danças, lutas e ginásticas, esporte).

Gostaríamos de chamar a atenção para dois pontos citados no parágrafo anterior que apontam para características importantes da iniciação à docência em EF. O primeiro aspecto está relacionado ao fato de que esses professores mostraram ter disposição, desejo e abertura ao trabalho coletivo. Para eles, a ausência desse espaço coletivo é motivo de desmotivação com o trabalho na escola, de sentimento de solidão e isolamento, que inibe experiência de descoberta da profissão e potencializa o choque da realidade. Esse achado da pesquisa mostra-se diferente da crítica que a literatura vem fazendo acerca de uma das características negativas do trabalho docente na escola: o individualismo da socialização profissional docente (LORTIE, 1975). Na opinião do autor, a forma celular da organização escolar e a ecologia de distribuição do espaço e do tempo na escola põem as interações entre os professores à margem de seu trabalho diário. A própria arquitetura escolar que se organiza na escola em módulos independentes favorece esse isolamento e/ou exposição. Os professores, assim, acabam por não compartilharem com seus pares a sua cultura técnica. As maiores recompensas psíquicas dos professores se obtêm no isolamento de seus pares, que cuidam muito para não negociar ou diluir as barreiras existentes entre as salas de aula.

Os professores pesquisados, em função do não reconhecimento cultural dos conteúdos da EF por parte dos agentes escolares, vislumbram o trabalho coletivo como uma das únicas maneiras de instituir vínculos com a escola, de serem reconhecidos como professores. A maioria das falas dos nossos depoentes destaca a importância de espaços de partilha de projetos e se ressentem quando esses não existem. Tal postura se apresenta para esses docentes como alternativa importante de apoio e de estímulo ao trabalho pedagógico que favoreceriam progressão mais confortável e estável na carreira e como alternativa de reconhecimento curricular, ante esse isolamento curricular da EF imposto pela cultura escolar. 
Soma-se a isso o fato de que a arquitetura escolar impõe aos professores de EF exposição física não vista nas demais disciplinas da escola. A forma celular da organização escolar, que contribui para inibir o trabalho coletivo, a segurança e a autonomia no trabalho pedagógico, é de certa forma relativizada no caso da EF. Os professores da nossa pesquisa relatam que se sentem expostos nas suas ações de ensino já que não existem em suas aulas as paredes que bloqueiam ou impedem os demais atores da escola de verem o que fazem ou deixam de fazer em suas classes. Os dados da nossa pesquisa mostram que essa exposição física do trabalho dos professores de EF acaba por relativizar possíveis receios de partilhar o seu trabalho com os demais atores escolares. Parece haver disposição maior desses professores para tal ou esses se sentem mais confortáveis ante o trabalho coletivo para com ele desenvolver ações com vistas ao desenvolvimento profissional ao longo da carreira.

O segundo ponto que queremos colocar em relevo se refere à relação que esses docentes têm com o conhecimento específico da EF. Para muitos deles, a construção de pontes entre o conteúdo da sua disciplina específica e a aprendizagem dos estudantes passa muitas vezes por um conhecimento do conteúdo que não se restringe a um domínio conceitual deles. A necessidade de dominar corporalmente os conteúdos da EF como elemento constituinte do ato de ensinar aparece como gerador de angústias, insegurança e estresse. Conhecer corporalmente os conteúdos da EF ou ter constituído um saber-fazer corporal é algo que limita e, ao mesmo tempo, desafia os professores em seu trabalho na escola.

Assim, os saberes de ordem corporal constituem, para os professores de EF, parte importante do que a literatura tem denominado de "conhecimento didático do conteúdo" (SHULMAN, 1987). Este conhecimento do professor reúne os tópicos ensinados regularmente em uma matéria específica, suas formas úteis de representação, as analogias, ilustrações, exemplos, explicações, e demonstrações - resumindo, as formas de representação e formulação do assunto que o torna compreensível. Tal conhecimento se vincula com a forma como os professores ajudam os estudantes a compreender determinado conteúdo. O conhecimento didático 
do conteúdo insere a forma de organizar o conhecimento disciplinar, os problemas que emergem e a adaptação dos estudantes com a diversidade de interesses e habilidades. Uma vez que não existe uma forma única e poderosa de representação, o professor deve ter à mão um equipamento genuíno de formas alternativas de representação, alguns dos quais derivam da pesquisa, enquanto outros são originados na sabedoria da prática. (SHULMAN, 1987).

A relação de intimidade corporal com os temas de ensino da EF apresenta-se como desafio à construção do conhecimento didático do conteúdo neste campo de intervenção pedagógica. São conhecimentos fundantes à construção de ações didáticas com vistas ao ensino mais "seguro” em EF. Desta forma, o domínio dos conteúdos da Educação Física para transformá-los em objetos didáticos passíveis de serem aprendidos pelos estudantes passa necessariamente pela descoberta ou redescoberta dessas práticas corporais, via a experimentação corporal e o domínio de algumas de suas destrezas motoras. A ampliação do repertório de saberes de ordem corporal mostrou-se significativo ao processo de aprendizagem docente em EF. Tais aprendizagens parecem ser ter como fonte primeira a sabedoria da prática, seja em vivências anteriores e externas à escola, seja em experimentações provocadas pelos professores, isto é, as máximas que guiam (ou fornecem racionalizações reflexas para) as práticas de professores na busca de representar e formular os conteúdos da EF para os alunos. Tal achado nos instiga a pensar outras formas de organização dos currículos dos programas de formação inicial e continuada que geralmente enfatizam o tratamento de saberes de ordem teórico-conceitual, em detrimento de experiências de aprendizagens construídas também pela construção de saberes via a experimentação corporal.

Entendemos, assim, que o conhecimento didático do conteúdo em Educação Física está ligado necessariamente às experiências de aprendizagem que dialogam com outras relações epistêmicas com o saber e o aprender. Sobre esse ponto, vale citar a reflexão realizada por Charlot (2000) acerca da relação com o saber. Para esse autor, aprender pode ser também dominar uma atividade ou capacitar-se a utilizar um objeto de 
forma pertinente. Não é apenas passar da não posse à posse de um objeto (o saber), mas sim do não domínio ao domínio de uma atividade. Esse domínio se inscreve no corpo. O sujeito epistêmico e, então, o sujeito encarnado em um corpo, entendendo-se por isso, no caso, não um sistema de órgãos distintos da alma, mas, sim, o corpo como foi definido por Merleua Ponty. O corpo é um lugar de apropriação do mundo, um conjunto de significações vivenciadas, um sistema de ações em direção ao mundo, aberto às instituições reais, mas também virtuais. O corpo é sujeito, conquanto engajado no movimento da existência, na qualidade de habitante do espaço e do tempo. Existe, assim, um Eu nessa relação epistêmica com o aprender, mas não é o Eu reflexivo que abre um universo de saberes-objetos; é um Eu imerso em dada situação, um Eu que é corpo, percepção, sistema de atos em um mundo correlato de seus atos (com possibilidades de agir, como valor de certas ações como efeito dos atos). Isso é o que o autor chama de "imbricação do Eu na situação", ou seja, o processo epistêmico em que o aprender é o domínio de uma atividade "engajada" no mundo.

Os achados dessa pesquisa apontam para o caráter situado da inserção profissional de professores iniciantes de Educação Física. Tais professores vivem situações, dilemas e possibilidades de inserção e aprendizagem profissional que são, em muitos aspectos, muitos próprios do contexto de ensino dessa disciplina na escola. Contexto esse marcado pelo ensino e aprendizagem de conteúdos singulares (as práticas corporais), pelas condições ambientais das salas de aula onde esses professores geralmente lecionam, pelo tipo de material didático utilizado, pelas interações estabelecidas com os alunos e pelo lugar que a EF ocupa na hierarquia dos saberes escolares.

Não obstante reconhecer que os professores iniciantes de EF vivem os mesmos dilemas profissionais que os demais professores da escola (solidão, stress, conflitos com os alunos, invisibilidade, falta de apoio institucional, péssimas condições de trabalho, carreira pouca atrativa e salários indignos), faz-se necessário, por outro lado, evidenciar que existem singularidades nas formas de inserção e desenvolvimento profissional docente. Reconhecer essas realidades situadas nos parece ser uma referência 
fundamental à produção de políticas de indução, retenção e desenvolvimento profissional dos professores iniciantes que garanta aos mesmos o pleno direito de conhecerem e amadurecerem dentro da profissão.

\section{Referências}

ARROYO, M. G. Ofício de mestre: imagens e auto-imagens. Petrópolis: Vozes, 2000.

BRACHT, V.; FARIA, B. A. A cultura escolar e o ensino da Educação Física: reflexões a partir da teoria de do reconhecimento de Axel Honneth. In: SANTOS, Lucíola L. C. P. S. et. al. Convergências e tensões no campo da formação e do trabalho docente. Belo Horizonte: Autêntica, 2010.

COCHRAN-SMITH, M. Trends and challenges in teacher education: National and international perspectives in Waldron, F., Smith, J. Dooley, T., \& Fitzpatrick, M. (eds.), Reimagining initial teacher education: Perspectives on transformation (pp. 29-53). Dublin: Liffey Press, 2013.

CHARLOT, B. Da relação com o saber: elementos para uma teoria. Porto Alegre: Ed. Penso, 2000.

FARIA, B. A., BRACHT, V., MACHADO, T. S., ALMEIDA, U. R, MACHADO, F. X. Inovação pedagógica na educação física: o que aprender com práticas bem sucedidas? In: XVI Congresso Brasileiro de Ciências do Esporte/III Congresso Internacional de Ciências do Esporte, 2009, Salvador. Formação em Educação Física e Ciências do Esporte: políticas e cotidiano, 2009. Disponível em: http:// cbce.tempsite.ws/congressos/index.php/CONBRACE/XVI/schedConf/presentat ions? searchField=\&searchMatch=\&search $=\&$ track $=22$

FERREIRA, L. A. O professor de Educação Física no primeiro ano da carreira: análise da aprendizagem profissional a partir da promoção de um programa de iniciação à docência. Tese de Doutorado. São Carlos: Universidade Federal de São Carlos, 2005. 
FONTANA, R. C. Trabalho e subjetividade: nos rituais da iniciação, a constituição do ser professora. Caderno CEDES [online], vol. 20, no. 50, abr. 2000. Disponível em: <http: //www.scielo.br. Acesso em: 26 out. 2004.

FEIMAN-NEMSER, S.; FLODER, R. E. Cultural aspects of teaching. In: WITTOCK, M. C. (Dir.). Handbook of research on teaching. $3^{\text {rd }}$. edition, p. 505-526. New York: Macmillan, 1986.

GARIGLIO, J. A. A cultura docente de professores de Educação Física de uma escola profissionalizante: Saberes e práticas em contexto de ações situadas. 2004. 275 f. Tese (Doutorado em Educação) - Departamento de Educação, PUC-Rio, Rio de Janeiro, 2004.

GOLD, Y. Beginning teacher support - Attrotion, mentoring, and induction. In: SIKULA, J.(DIR.). Handbook of research Education. New York: Macmillan, 1996.

GUARNIERI, M. R. Tornando-se professor: o início na carreira docente e a consolidação da profissão. Tese (Doutorado em Educação) — Universidade Federal de São Carlos, São Carlos, 1996.

HUBERMAN, M. Cycle de vie et formation. Vevey: Éditions Delta, 1974.

HUBERMAN, M. O ciclo de vida profissional dos professores. In: NÓVOA, António (Org.). Vida de professores. p. 31 a 62. Porto: Porto Editora, 1992.

JEBER, L. J. A educação física no ensino fundamental: o lugar ocupado na hierarquia dos saberes escolares. 1996. Dissertação (Mestrado em Educação) - Faculdade de Educação, Universidade Federal de Minas Gerais, Belo Horizonte, 1996.

LESSARD, C; TARDIF, M. Les identities enseignantes: analyse de facteurs de différenciation du corps enseignant québécois 1960- 1990. Editions du CRP, Université de Sherbrooke, 2003.

LORTIE, D. (1975). School Teachers: A sociological study. Chicago: University of Chicago Press. 
MACHADO, T. S. ; BRACHT, V. ; MORAES, C. A. ; ALMEIDA, F. Q. ; SILVA, M. A. As práticas de desinvestimento pedagógico na educação física escolar. In: XVI Congresso Brasileiro de Ciências do Esporte/III Congresso Internacional de Ciências do Esporte, 2009, Salvador. Formação em Educação Física e Ciências do Esporte: políticas e cotidiano, 2009. Disponível em: http://cbce.tempsite.ws/ congressos/index.php/CONBRACE/XVI/schedConf/presentations?searchField= \&searchMatch $=\&$ search $=\& \operatorname{track}=22$

MARCELO-GARCIA, C. Políticas de inserción a la docência: De eslabón perdido a puente para el desarrollo profesional docente. GTD-PREAL, 2007.

MARCELO-GARCIA, C. A identidade docente: constantes e desafios. Revista Brasileira de Pesquisa em Formação de Professores, vol 1, n. 1 Ago-Dez. 2009.

MERSETH, K.K. Case studies and teacher education. Teacher Education Quartely 17(1), 1990, pp.53-61.

MIZUKAMI, M.G.N. Casos de ensino e aprendizagem profissional da docência. In: ABRAMOWICZ,A.; MELLO, R.R. (orgs.) Educação: pesquisas e práticas. Campinas, SP: Papirus, 2000, pp.139-61.

SCHÖN, D.A. Formar professores como profissionais reflexivos. In: NÓVOA, A. (org.). Professores e a sua formação,1992, pp.79-93.

SHULMAN, L.S. Toward a pedagogy of cases. In: SHULMAN, J.H. (org.) Case methods in teacher education. New York: Teacher's College Press, 1992.

SHULMAN, L. L. Knowledge and teaching: foundations of the new reform. Harvard Educational Review. v. 57, n., 1. Feb. 1987. p. 1-22.

TARDIF, M.; RAYMOND, D. Saberes, tempo e aprendizagem do trabalho no magistério. Educ. Soc., v. 21. n. 73. dez. 2000.

TARDIF, M. Saberes docentes e formação profissional. Petrópolis, RJ: Vozes, 2002.

VEENMAN, S. Perceived problems of beginning teachers. Review of Educational Reserch, v. 54, n. 2, p. 143-178, 1984. 
YOUNG, M. Uma abordagem do estudo dos programas enquanto fenômenos do conhecimento socialmente organizado. In: GRÁCIO, Sergio; STOER, Stephen. Sociologia da Educação II - A construção social das práticas educativas. Belo Horizonte: Horizontes, 1982. p. 151-187.

ZABALZA, M. A. Diários de aula. Porto/Portugal: Porto Editora, 1994.

Recebido: 15/09/2014

Received: 09/15/2014

Aprovado: 20/03/2015 Approved: 03/20/2015 